\title{
PEDRO MARTÍN MARTÍNEZ, PROFESOR DE ANATOMÍA DEL HOSPITAL GENERAL DE MADRID
}

\author{
Ataulfo Saíz Carrero.
}

Especialista Senior de Urología (Uubilado). Hospital General Universitario Gregorio Marañón. Madrid. España.

\begin{abstract}
Resumen.- OBJETIVO: El estudio de las obras anatómicas escritas por Martín Martínez y su relación con la Urología. Así como, la apreciación de su abierta mentalidad científica y escéptica en un entorno histórico aún imbuido de escolasticismo y dogmatismo.
\end{abstract}

MÉTODOS: Se revisaron algunas obras de Martín Martínez, principalmente el tratado Anatomía Completa del Hombre, texto íntegro obtenido de la página electrónica de la Biblioteca de la Universidad Complutense de Madrid, y las obras de otros autores de su tiempo.

RESULTADOS: Se constata la personalidad médica y filosófica de Martín Martínez y su influencia en el saber médico del primer cuarto del siglo XVIII en la Corte
Española. Se aprecia la importancia que tuvo, como Profesor de Anatomía, en el funcionamiento y desarrollo del Anfiteatro Anatómico madrileño del Hospital General y su repercusión positiva en la formación de estudiantes y cirujanos de su época y de años posteriores. A ello contribuyó el que sus obras estuvieran escritas en castellano.

CONCLUSIONES: Aunque no se le puede considerar como una personalidad científica sobresaliente, comparado con autores de otros países europeos, hay que reconocerle gran mérito por su labor aperturista y antidogmática ante la mentalidad médica estancada en el "servilismo" y en el estudio de los autores clásicos de siglos anteriores.

Palabras clave: Anatomía. Martín Martínez. España Siglo XVIII. Historia de la Urología.

Summary.- OBJECTIVES: The study of the anatomical works written by Martín Martinez and his relationship with urology. Also, the appreciation of his open scientific mentality and scepticism in a historic environment imbued of a scholastic spirit and dogmatism.

METHODS: Several Martin Martinez's works were reviewed, mainly the treaty Complete human anatomy, entire text obtained from the electronic page of the Complutense University library, and also the words from other authors of his time.

RESULTS: The medical and philosophical personality of Martin Martinez and his influence in the medical knowledge in the Spanish Court during the first quarter of the 18th century are ascertained. The importance he had as Professor of anatomy in the functioning and development of the Madrid's Anatomical Amphitheater in the 
General Hospital and his positive repercussion on the training of students and surgeons of that time and posterior years is appreciated. Writing his works in Spanish contributed to it.

CONCLUSIONS: Although he cannot be considered an outstanding scientific personality in comparison with authors from other European countries, he must be recognized for his great merit with his open mind and his labour against dogmatism in front of the blocked-in-servility medical mentality, and also in the study of classic authors from previous centuries.

Keywords: Anatomy. Martin Martinez. Spain XVII Century. History of Urology.

\section{INTRODUCCIÓN}

Escribía Gregorio Marañón en 1934: "Ni uno solo, ni uno de los médicos del primer tercio del siglo XVIII ha dejado un ápice de gloria legítima a la ciencia española. Adscritos a las sectas sistemáticas de Hipócrates, de Gasendo, de los químicos, etc., se eternizaban en disputas disparatadas, sin acercarse a observar al enfermo; $y$, en tanto, este se moría, en el mejor caso falto de asistencia, porque muchas veces se aceleraba su fin con los bárbaras sangrías y con las dietas de hambre mas rigurosas (...) Así sucedió, que gentes no médicas invadieron su terreno a los doctores, y tal vez, por lo mismo que no se había incapacitado para discurrir en las aulas, alcanzaron reputación superior a la de los más conspicuos galenos: tal sucedió al padre Feijoo, solicitado por enfermos de toda la Península... "" (12) (Figura 1).

Pero después, nuevos estudios como los aportados por el profesor lópez Piñero, han hecho cambiar, parcialmente, las ideas negativas de esta época pues estaban basadas en la medicina oficial, que verdaderamente sí estaba estancada ${ }^{2}$.

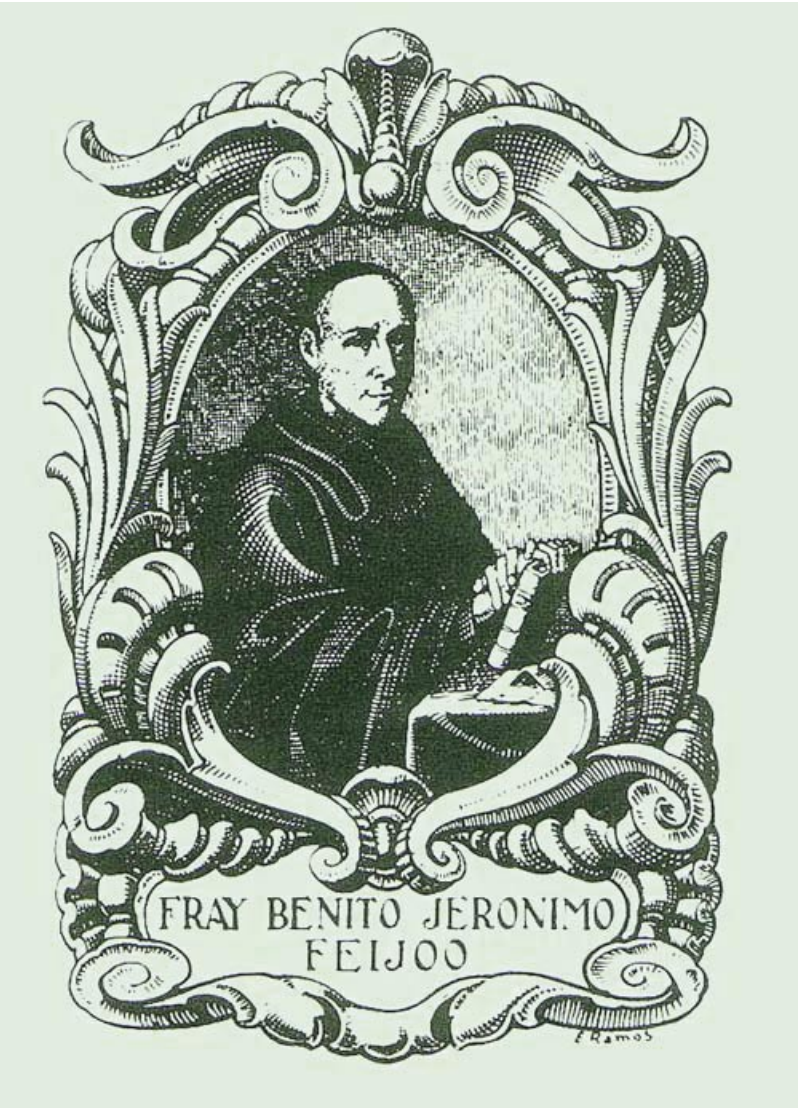

FIGURA 1. Benito Jerónimo Feijoo (1676-1764). Gran representante del criticismo en la primera mitad del s. XVIII.

La ciencia institucional, la que se enseñaba en las universidades era inmovilista y desfasada; y además, incapaz de renovarse, atacaba a los que lo intentaban hacer. No fue impulsora de nuevos avances, pero estos, sí surgieron en otros ámbitos científicos y filosóficos, al margen del saber escolástico (20).

Este distanciamiento entre lo oficial y lo oficioso, entre lo escolástico y lo moderno, se observa principalmente en el ejercicio de la medicina.

\footnotetext{
'Se considera a Feijoo como uno los grandes filósofos en lengua española, que seguía las doctrinas de Bacon de Verulamio basadas en el empirismo. Fue un filósofo influyente de raíces aristotélicas que por tanto, abogaba por el método experimental, al cual daba más valor que cualquier deducción racional. Además de combatir la ignorancia, el padre Feijoo luchó contra las supersticiones que reinaban en todas las clases populares, así como contra los peligrosos tratamientos que realizaban algunos de los médicos de su época pues, tenía sólidos conocimientos de esta ciencia. Difundió cultura, ciencia y propuso reformas contra ese ambiente pobre. Sus polémicas con otros escritores fueron muchas (7).

${ }^{2}$ En un texto de Diego de Torres Villarroel (que era "un pícaro de plazuela" según Marañón) se aprecia el estado desastroso en el que estaba la Universidad en aquellas épocas: "...todas las cáthedras de las universidades estaban vacantes, y se padecía en ellas una infame ignorancia. Una figura geométrica se miraba en este tiempo como las brujerías y las tentaciones de San Antón, y en cada círculo se les antojaba una caldera donde hervían a borbotones los pactos y los comercios con el demonio (...), pedí a la Universidad la sustitución de la cátedra de Matemáticas, que estuvo sin maestro treinta años y sin enseñanza más de ciento cincuenta..." (21).
} 


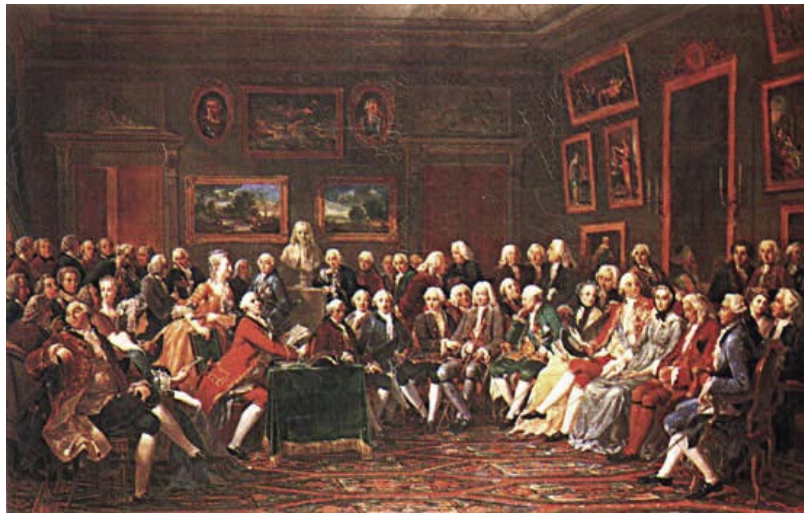

FIGURA 2. Reunión cultural francesa en la época de Martín Martínez, modelo de las que se realizaban también en España.

Había en aquella época dos grupos de facultativos: los médicos de la Universidad y los rivalidados. Los primeros, también llamados galenistas y escolásticos, eran más teóricos que prácticos; ellos mismos se llamaban "racionales" y "dogmáticos". Los médicos rivalidados no habían pasado por la Universidad, pero habían practicado con otros médicos y así obtenían la reválida para poder ejercer. Se ocupaban menos de la erudición que de las novedades médicas que venían del resto de Europa.

La formación de los estudiantes de medicina se reducía a la lectura y comentarios de algunos clásicos autores griegos y medievales. La carrera duraba menos de cuatro años en los que se estudiaba mucha metafísica, mucha lógica y se hacía un profundo análisis del Corpus Hippocraticum, de los tratados de Galeno y del Canon de Avicena. Para los cirujanos, era obligatorio estudiar el texto medieval de Guido de Chauliac, que era aprendido de memoria sin una experiencia clínica (20).

Sólo la teología y la metafísica tenían cierta actividad intelectual. Feijoo opinaba que la medicina española mejoraría si se separase de la metafísica a la que estaba asociada.

A finales del siglo XVII y comienzo del XVIII empezaron a aparecer nuevas ideas que se introdujeron en España en un ambiente cortesano o entre las

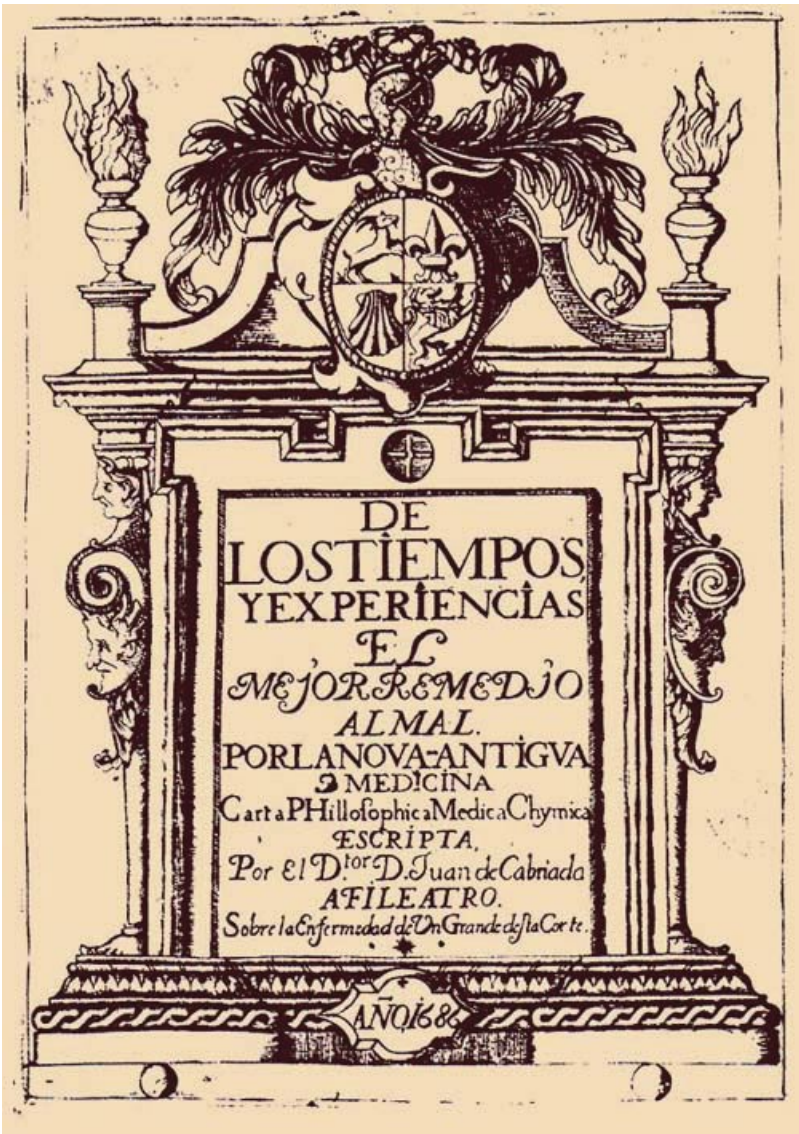

FIGURA 3. Libro de Juan de Cabriada (1665-1714).

clases elevadas. Eran "tertulias" que tenían lugar en casa de nobles. Estaban a cargo de estudiosos independientes e incluso de Sociedades o Academias al margen del ámbito oficial, pues nada tenían que ver con las Cátedras Universitarias ${ }^{3}$ (Figura 2).

Los tres principales renovadores de nuestra Ciencia a finales del siglo XVII y principios del XVIII fueron los médicos Juan de Cabriada (Figura 3), Diego Mateo Zapata (Figura 4) y Pedro Martín Martínez.

Este último, que nunca llegó a hacer oposiciones a cátedras universitarias, fue miembro y Presidente de una de estas Sociedades, gran foco español de renovación científica, la Regia Sociedad de Medicina y demás Ciencias de Sevilla, que tuvo como enemigo

\footnotetext{
${ }^{3}$ Algunas de estas Sociedades Científicas tenían cláusulas en donde se decía que, para ser Doctor, sólo hacía falta saber filosofía y medicina galénica, pero para ser miembro de esa Sociedad se requería estar versado en amplios conocimientos modernos, continuamente renovados. Las investigaciones que hacían los miembros de esta academia eran muy variadas. Su pensamiento era, o bien cartesiano, o bien gassendista, o baconiano. Era llamativo que la mayoría de las ideas de estos autores iban en contra de la idea del hombre defendida por la escolástica, por lo que esta vio en ellos un peligro para la recta explicación de los dogmas, lo que explica la resistencia que hubo siempre hacia las ideas más modernas de Europa. Así se comprende que el pensamiento moderno llegará tardíamente a España.
} 
mortal, durante muchos años, la propia Universidad hispalense. En esta Sociedad, fundada en 1697 por siete personalidades, hubo un encuentro entre la medicina y la filosofía. Tuvo su gran auge en el siglo XVIII. En ella se autorizaba la práctica de autopsias de ajusticiados y fallecidos sin familia $(7,20)$.

Fue una suerte que se organizara una Institución dotada de tan alto espíritu y con tan amplio plan de trabajos. Los médicos fundadores de esta Institución lo hicieron a imitación de la Academia de París con intención de saber lo que pasaba fuera de España. En la Regia Sociedad de Medicina y demás Ciencias de Sevilla nadie hablaba ex cátedra ni se limitaban tercamente a una opinión; eran antidogmáticos $(6,16)$.

A los personajes que al margen de la Universidad y desde las mencionadas Academias hicieron esta labor les llamaron, peyorativamente, "novatores". Ellos tenían una conciencia clara del atraso que

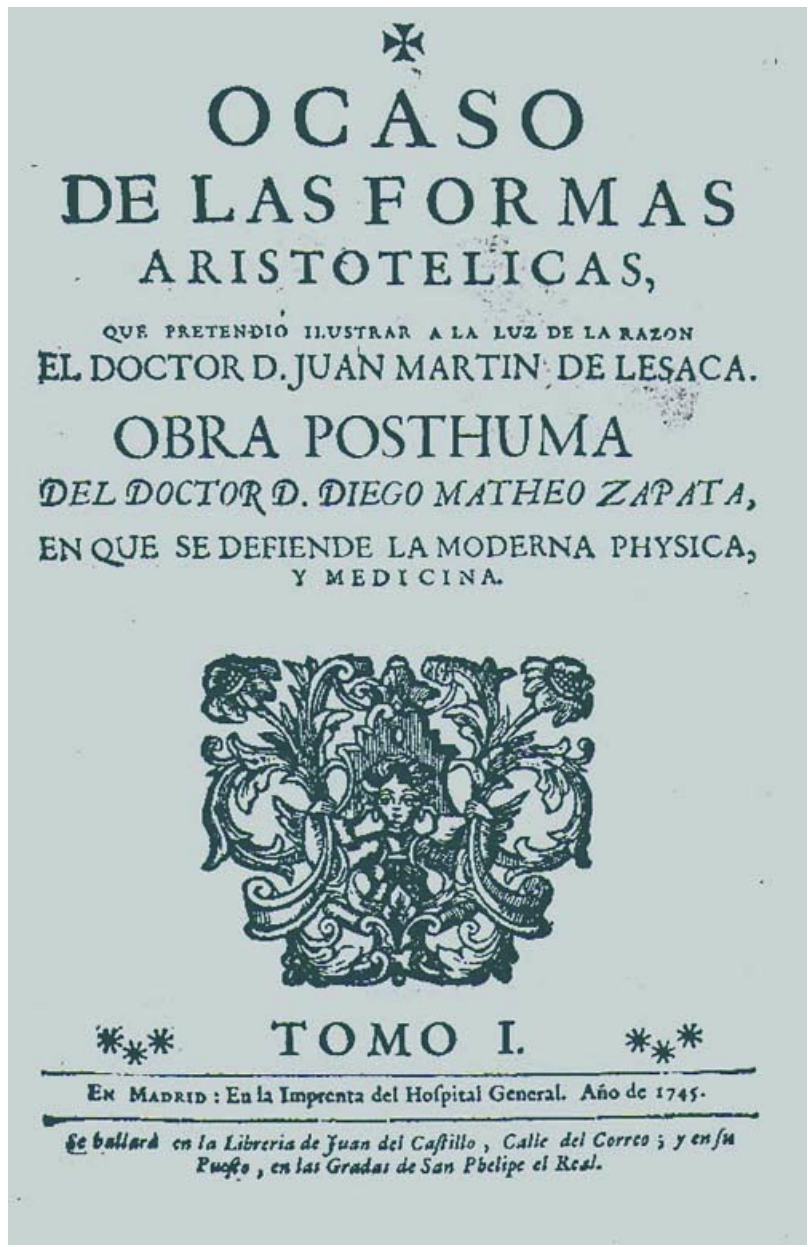

FIGURA 4. Libro de Diego Mateo Zapata (1664-1745). presentaba España con respecto a Europa y tuvieron que luchar contra una gran oposición que defendía los saberes tradicionales $(3,6)$.

Esta variedad de criterios médicos fue motivo de confusión para los enfermos. Tenían grandes dudas en el momento de acudir a un facultativo, y además, muchos no creían en su poder curativo. Esto se refleja, claramente, en algunos versos de aquella época, como los siguientes:

Si acaso, por accidente, - enfermares con rigor, sufre, y calla con paciencia, - porque es peor el Doctor. En cualquier enfermedad, - resístete, y hazte fuerte, y no llames al Doctor, - que es Espejo de la muerte (20).

A esto hay que sumar la aparente solemnidad de la mayoría de aquellos médicos, su pedantería, sus ineficaces y monótonos tratamientos, y su afán por el lucro. Lo ironiza perfectamente Quevedo en el famoso entremés El médico:

¿Tú sabes qué es Medicina? - Sangrar ayer, purgar hoy, mañana ventosas secas, - y es otro "kirie-eleisón"; dar dineros el concejo, - presentes el que sanó por milagro o por ventura; - barbar bien, comer mejor, contradecir opiniones, - culpar siempre al que murió

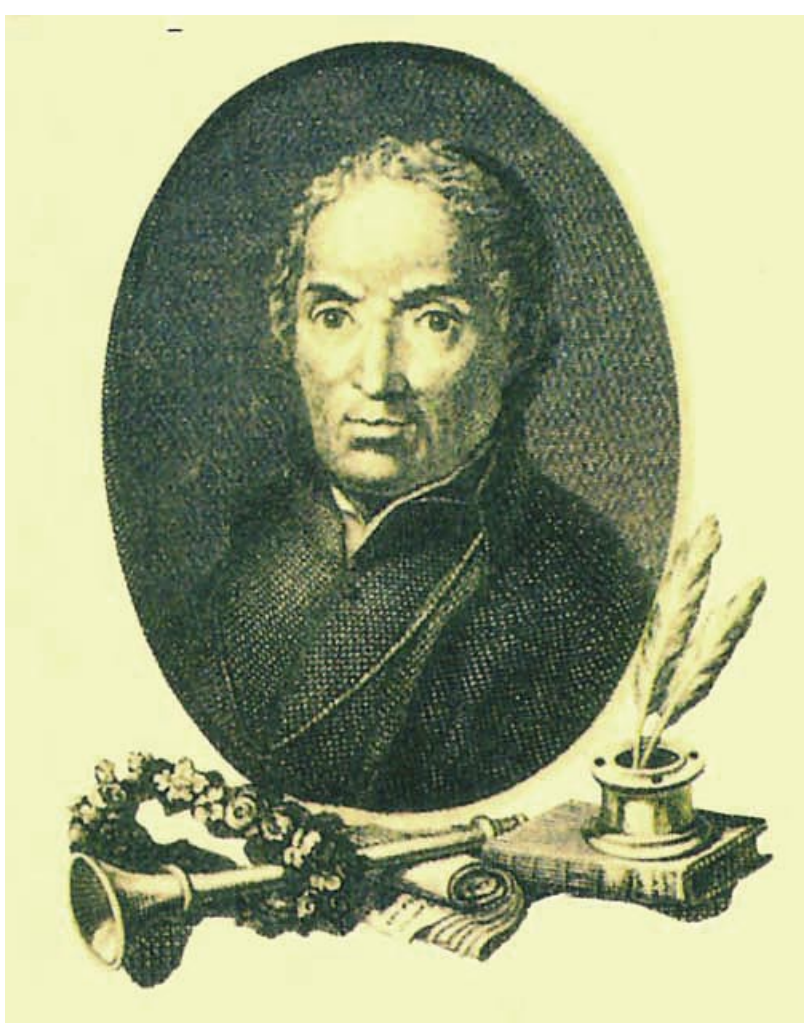

FIGURA 5. José Francisco de Isla y Rojo (1703-1781). llustre autor de "La historia del famoso predicador Fray Gerundio de Campazas, alias Zotes". 


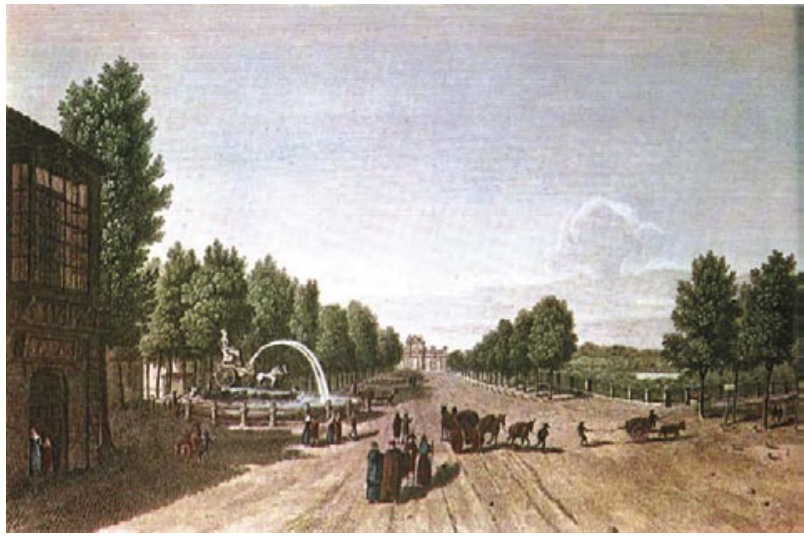

FIGURA 6. Madrid en el siglo XVIII.

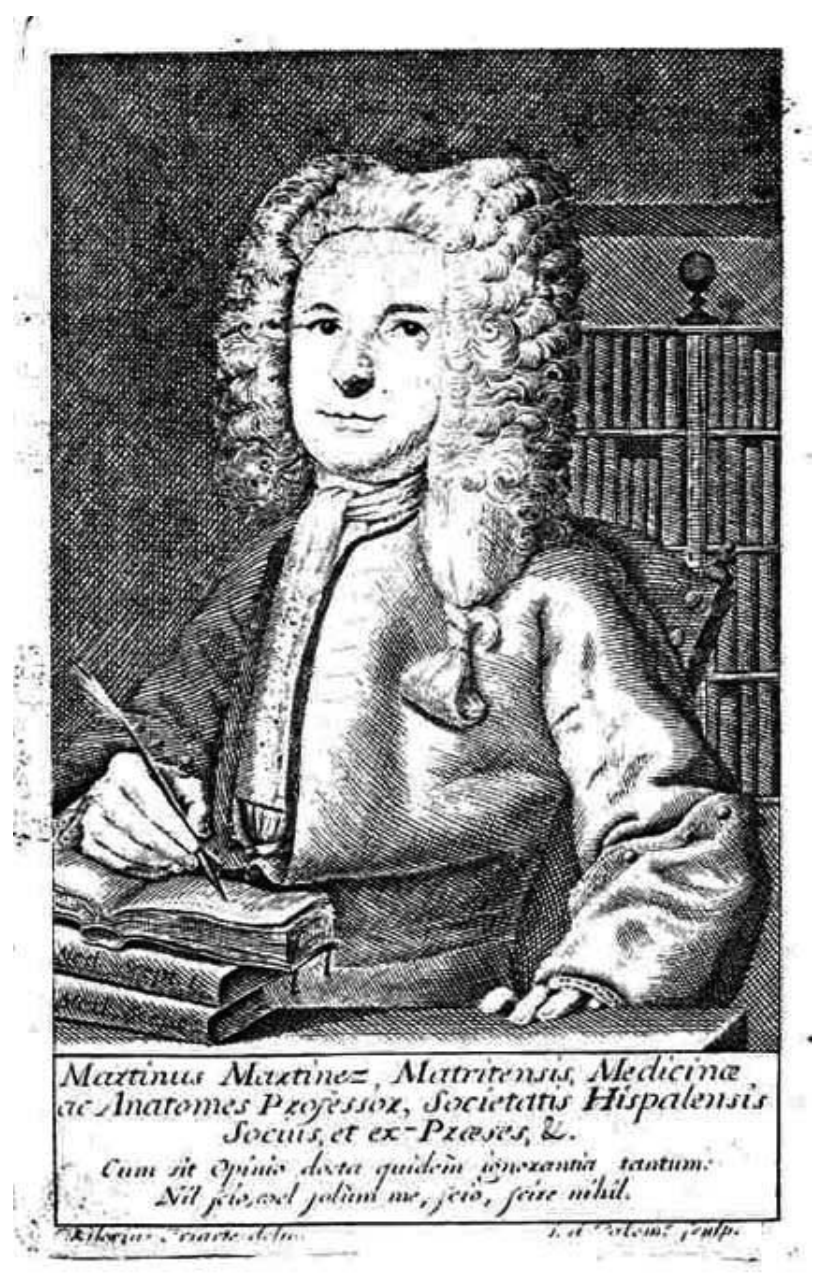

FIGURA 7. Pedro Martín Martínez (1684-1734). de que era desordenado, - y ordenar su talegón; que con esto y buena mula, - matar cada año un lechón, y veinte amigos enfermos, - no hay Sócrates como yo.

A ello contribuía también la opinión nefasta que contra los médicos tenían otros escritores célebres de la época, como el padre Feijoo, el padre Martín Sarmiento y el jesuita José Francisco de Isla (Figura 5). Este, en su obra Cartas de Juan de la Encina (1732) hace una mordaz sátira contra ellos ${ }^{4}(10)$.

La reforma tan necesitada de la Universidad no se inició hasta Carlos III. Los cuatro años de medicina contaron con materias más modernizadas. Después de aprobados estas, para poder ejercer era necesario un quinto curso de pasantía, ayudando a un catedrático y repasando estudios de química. Para un mayor grado académico había que hacer otros tres años sobre estudios químicos, farmacéuticos y botánicos (20).

\section{BIOGRAFÍA DE MARTÍN MARTÍNEZ}

Nació en Madrid el 11 de noviembre de 1684 y murió también en la Corte el 9 de octubre de 1734 a los 50 años de edad (Figura 6).

Estudió medicina en la universidad de Alcalá de Henares, donde se doctoró (Figura 7).

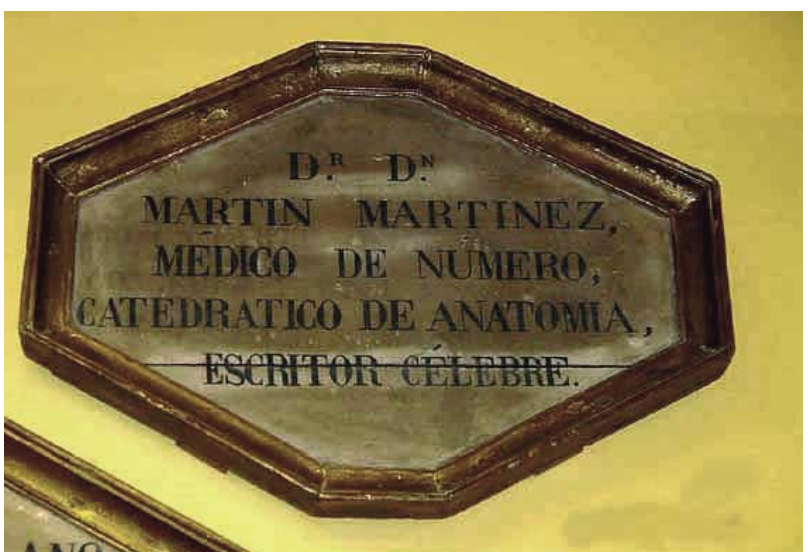

FIGURA 8. Placa de madera que junto con otras se encontraban situadas en uno de los pasillos del antiguo Hospital Provincial de Madrid.

\footnotetext{
${ }^{4}$ En otros de sus escritos, como en Colección de papeles crítico-apologéticos y en El Tapaboca, se encuentran frases del Padre Isla con fina y graciosa ironía contra la profesión médica: "Ios Pontífices, Reyes y Universidades, con justo título fomentan a los profesores esta Facultad, porque de otra manera no cupieran los hombres en el mundo, pero ya llegan a tantos los despoblados, que es primero cercenar los médicos, y mantener sólo los necesarios para que conserve la multitud su equilibrio". Y en relación a su obra Fray Gerundio de Campazas, esperando verla publicada en el invierno de 1755, decía: "si un terremoto no me engulle o un médico no me despacha". Refiriéndose a los duelos a muerte por una dama, opina: "pues ya se sabe que las mujeres han muerto a más hombres en la calle, que los médicos en la cama".
} 
Desde 1706 (a los 22 años) ocupó una plaza de médico de número por oposición, en el Hospital General de Madrid, en donde llegó a ser Profesor de Anatomía desde 1707 al 1734 (15) (Figura 8).

Fue, además de Presidente de la Regia Sociedad de Medicina y demás Ciencias de Sevilla, Médico Honorario de Familia, Médico de Cámara de Felipe V y Examinador del Protomedicato 5 (17).

Debido a esta relación con la Corte, se vio influido por las corrientes culturales europeas, lo que se manifiesta en sus escritos, que poseen un marcado carácter renovador.

Fue uno de los médicos españoles más ilustrados del siglo XVIII' ${ }^{6}$. Tenía una cultura enciclopédica y un espíritu reflexivo e ingenioso. Gran conocedor de las lenguas clásicas, así como de la Gramática Castellana, por lo que fue llamado"Cicerón de los castellanos". Uno de sus grandes méritos fue que sustituyó el latín por la lengua castellana en sus libros; de este modo sacó los saberes médicos del entorno académico ${ }^{7}(1)$.

Además defendió la utilización del español frente a los galicismos que la moda francesa estaba imponiendo. Sin embargo, esto no fue impedimento para que difundiera en España las novedades anatómicas y quirúrgicas de la medicina de Francia (17).

Fue muy criticado y muy envidiado, sobre todo por facultativos no madrileños, pues estos suponían que los que trabajaban en la Corte estaban protegidos por los últimos Austrias y los primeros Borbones. Los grandes disgustos que le proporcionaron sus rencillas profesionales, pudieran haber contribuido a su muerte prematura a los 50 años (1).

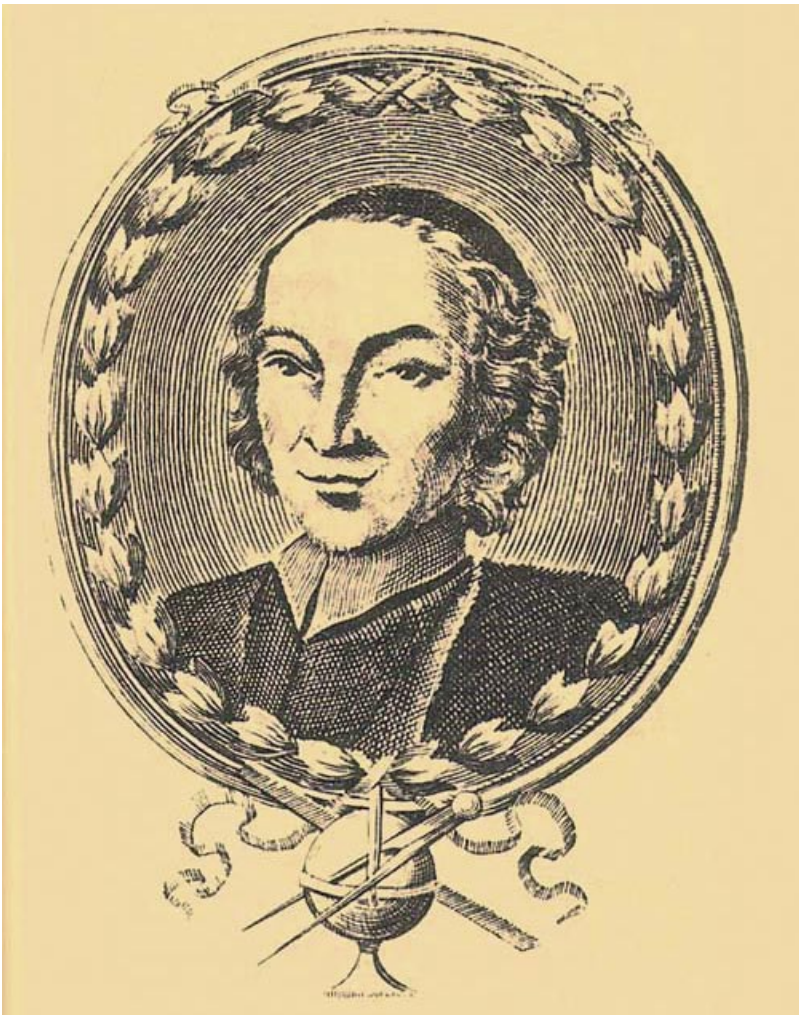

FIGURA 9. Diego de Torres y Villarroel (1693-1772). Persona polifacética: tuvo doce ocupaciones distintas, entre ellas la práctica médica.

\section{SU PENSAMIENTO MÉDICO Y FILOSÓFICO}

Aunque el inicio del siglo coincidió con un cambio dinástico que haría más fácil la conexión con los movimientos culturales de Europa, en nuestro país por aquel tiempo sólo florecía la escolástica.

El pensamiento moderno no estaba en manos de profesionales de la filosofía sino que era di-

\footnotetext{
${ }^{5}$ La institucionalización de los servicios sanitarios reales de la Corte Madrileña se produjo durante el reinado de Felipe II. Existían, ordenados jerárquicamente, los siguientes médicos: Médicos de Cámara, Médico de Familia, Cirujanos, Sangradores y Sangradores del Común. De los dos primeros grupos, se escogían las personas que conformaban el Real Tribunal del Protomedicato, que estaba formado por 6 médicos: tres Protomédicos y tres Examinadores. El cargo de Protomédico era vitalicio y a estos les correspondía presidir el Real Tribunal del Protomedicato. Su sucesión se hacía por orden de antigüedad entre el grupo de los Médicos de Cámara. Estos constituían la más alta categoría médica que se podía alcanzar en el Servicio Real. Eran los encargados de tratar cualquier tipo de enfermedad del Rey, la Reina y los Príncipes. Servían por semanas en Palacio, acudiendo cada semana uno de los contratados. Los Examinadores se encargaban de la realización de los exámenes para habilitar el ejercicio médico y farmacéutico. Su cargo era por dos años, por lo que había un turno de rotación entre los Médicos de Familia. Estos estaban encargados de la salud de todos los criados de la casa real, desde el Mayordomo Mayor hasta el último de los mozos de oficio. Servían por meses en lugar de por semanas (18).
}

- Sin embargo Marañón no opina lo mismo. Según él, fue un anatómico de tercera clase y un filósofo adocenado. "Los libros, tan renombrados y tan mediocres de Martín Martínez, dan idea de la falta absoluta de sentido pedagógico en que él encontró las Facultades, anárquicas, sin criterio y sin el más preciso material".

7 Como hacía un perfecto uso de la lengua castellana en sus escritos, fue incluido en el "Catálogo de los Escritores que pueden servir de Autoridad", publicado por la Academia de la Lengua, en Madrid en 1874. 
fundido principalmente por otros profesionales, como el caso de los médicos, fuera de la estructura oficial que era conservadora y eclesiástica (7).

Pedro Martín Martínez fue defensor del método experimental al que Feijoo se refiere repetidamente. Tenía grandes conocimientos anatómicos, fisiológicos y filosóficos. En muchas de sus obras usó el diálogo como modo de exponer sus ideas. Este diálogo surge entre médicos de diferente formación: un galénico, un químico y un escéptico. Será este último el que describa el método de "saber dudar, admitir la probabilidad y justificar el empleo de la lengua vernácula usual para que entienda todo el mundo" (6).

Intentó huir de abstracciones metafísicas y empleó sólo la recta experiencia, y no la razón, ni la autoridad de Dios y de la Iglesia. Tenían sus escritos un carácter ecléctico, pues sus ideas eran esencialmente escépticas, pero también expresaba elementos cartesianos con alguna resonancia escolástica. Era escéptico en su quehacer médico, o sea en lo referente a lo físico, pero dogmático en lo referente a la fe y materias metafísicas (3).

Renuncia al conocimiento de la "naturaleza" y duda del "conocimiento del mundo real dado el límite del conocimiento humano". Admite el mundo de la experiencia y de la apariencia, como base en una ciencia médica experimental y útil. Según él, "no se puede construir una ciencia física usando sólo el mero proceso mental".

Para Martínez, el hombre posee un cuerpo formado de elementos organizados pero además, "existe otra sustancia espiritual y pensativa, como informa la conciencia propia, y enseña la $\mathrm{Fe}^{\prime \prime}(3)$.

Intentó asemejar el pensar tradicional y el moderno, de conciliar lo religioso y lo filosófico. Esto se puede interpretar como un recurso de prudencia para introducir el pensamiento moderno en un ambiente hostil y así evitar el conflicto entre ciencia y ortodoxia. Pero a pesar de esta tendencia conciliadora, no pudo impedir que se viera envuelto en ataques y polémicas con algunos escolásticos, como lópez de Araujo, Juan Martín de Lesaca y Torres Villarroel (3) (Figura 9).

La importante figura médica y filosófica del doctor Martín Martínez habría desaparecido casi completamente si no hubiera salido en su defensa el padre Feijoo. (6) Contra los ataques que le hizo Bernardo López de Araujo en su libro "Centinela Médico-Aristotélica contra Scépticos", lo defendió con el libro "Apología del Escepticismo Médico8" (5).

El Doctor Juan Martín de Lesaca, médico del llustrísimo Cabildo de Toledo, en el capítulo último del libro que tituló "Apología Escolástica, en defensa de las Universidades de España, contra la Medicina Scéptica del doctor Martínez", críticó las dudas de Martín Martínez $z^{9}$ (4).

A lo largo de su vida escribió obras de muy variados temas: anatómicos, quirúrgicos, filosóficos y de curiosidades. Esta es su bibliografía ordenada cronológicamente.

- Noches anatómicas, o Anatomía compendiosa. Madrid 1716.

- Compendio y Examen Nuevo de Cirugía Moderna. Madrid, 1722. Ediciones posteriores con ligera modificación del título y texto ampliado fueron las de 1724, 1732, 1743, 1766, 1788 y 1797.

- Medicina scéptica y cirugía moderna, con un tratado de operaciones chirurgicas, Madrid, 1722.

- Discurso físico sobre si las víboras deben reputarse por carne o pescado en el sentido en que nuestra

${ }^{8}$ El doctor López de Araujo, también médico de los Reales Hospitales de la Corte, califica al doctor Martínez de "necio, loco e ignorante". A ello responde Feijoo, diciendo que él considera al Dr. Martínez, como de "persona de sutilísimo ingenio, solidisimo juicio, y admirable erudición". Le denomina "Águila de los ingenios". Refiriéndose a López Araujo dice que se admira qué ingenios pigmeos se empeñen en combatir gigantes y explica este ataque de Araujo a Martínez "como alguna pasión de envidia a los aplausos de él". En relación a su escepticismo le defiende Feijoo diciendo, que "no es absoluto y general el escepticismo del doctor Martínez". Dice que el libro de Aravjo es una "continuada impertinencia sin sustancia". (5)

${ }^{9}$ De este ataque también le defendió el P. Feijoo en su obra Theatro Crítico Universal, y refiriéndose al Dr. Lesaca pregunta:

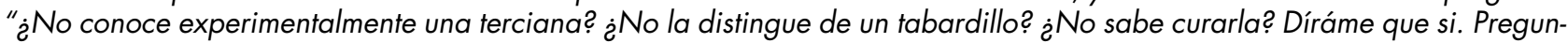
to más: ¿̇conoce su causa morbífica? Aunque me diga que si, yo sé ciertamente que no; salvo que Dios se le haya revelado". Y opina: "... a cada paso se halla que lo que éste decreta como conveniente para tal enfermedad, aquél lo condena por nocivo ", pues no hay un criterio único. Finaliza Feijoo diciendo: "...por lo demás tengo por útil y segura esta Medicina Escéptica, y digna de la pública luz, por ver si con este estímulo llega algún tiempo en que nuestras Escuelas Médicas enmienden el siniestro uso de sus estudios". (4) 
madre la Iglesia nos veda las carnes en días de abstinencia, Madrid 1723.

- Observatio rara de corde in monstroso infantido ubi obiter et noviter de motu cordis et sanguinis agitur. Madrid, 1723.

- Carta defensiva, que sobre el primer tomo del Teatro Crítico Universal, que dio a luz el Rmo. P. Mro. Fr. Benito Feijoo, le escribió su más ficionado amigo D. Martín Martínez. Madrid, $1726^{10}$.

- Juicio final de la Astrología, en defensa del Theatro Crítico Universal: dividido en tres discursos. Madrid, 1727.

- Anatomía Completa del Hombre. Madrid, 1728. Conoció ocho ediciones a lo largo siglo XVIII.

- Philosophia Sceptica : extracto de la physica antiqua, y moderna, recopilada en dialogos, entre un Aristotelico, Cartesiano, Gasendista, y Scéptico. Madrid, 1730 .

\section{SU OBRA ANATÓMICA}

En España, el renacer de la ciencia médica del siglo XVIII se reflejó en los primeros tratadistas de anatomía en España: Manuel de Porras (1716) y Martín Martínez (1728). Después siguieron los estudios de Antonio de Gimbernat (1793) y el tratado de Bonells y Lacaba (1796-1800). Esta puerta abierta a la ciencia se cerró durante el período de la Guerra de la Independencia y del reinado de Fernando VII $(1,9)$.

Este esplendor que tuvo la Anatomía se debió, en primer lugar, a que a la Corte española llegaron grandes profesionales extranjeros con el séquito del primer Borbón. Entre ellos, Florencio Kelli que se había educado en París. Realizó enseñanzas como "Dissector Regio" en la Cátedra del Anfiteatro Anatómico Madrileño del Hospital General (situado en sus sótanos), alrededor del año $1703(8,9)$ (Figura 10).

El primer Profesor de esta Cátedra fue, según algunos autores, José de Arboleda, que estuvo en el cargo pocos años y además sus clases eran muy irregulares; él mismo propuso a Martín Martínez como

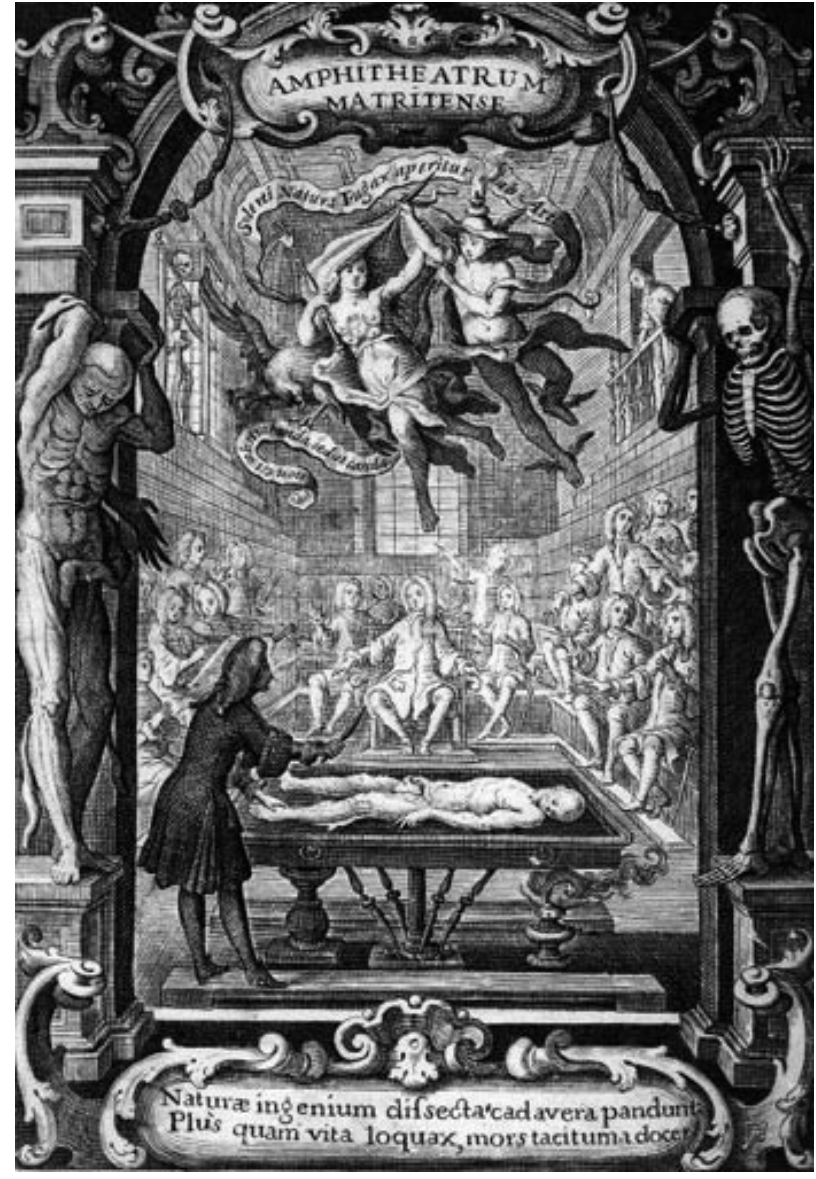

FIGURA 10. Portada de la primera edición de la Anatomía Completa del Hombre de Martín Martínez, en donde se ve representado el Anfiteatro de Anatomía del Hospital General de Madrid.

su sucesor, ya que este había hecho muchas disecciones en dicho Centro, aunque no era cirujano.

Según autores con investigaciones más recientes (Riera, Núñez Olarte y Aguinaba Manzanos), la enseñanza de la Anatomía en dicho Hospital se inició en 1689, al ser nombrado Médico de Familia el doctor Francisco Feu (Fecie), encargándosele que además ejercitarse la profesión anatómica. Posteriormente, con fuentes distintas, Pardo Tomás y Martínez Vidal han llegado a la misma conclusión.

Sucedió al doctor Feu el doctor Roque de Buendía y Dávila, que fue anterior a José Arboleda, o sea, que el Anfiteatro Anatómico del Hospital Gene-

\footnotetext{
10 En esta obra demuestra su gran cultura y su espíritu critico sobre algunas costumbres médicas de su tiempo, como por ejemplo la gran cantidad de sangrías que hacían algunos de sus colegas. Critica, también, el valor que el vulgo daba, con relación a padecer enfermedades, a las fases de la luna y a la aparición de eclipses y cometas. Al final defiende su profesión de algunas consideraciones peyorativas que había hecho Feijoo en el "Theatro Crítico Universal" contra los médicos en general (13).
} 
ral se inició en 1689, en lugar de 1705 como dicen los primeros investigadores ${ }^{11}$ (15).

En las Constituciones del Hospital de 1705, se lee:

"Que desde el mes de septiembre, hasta el mes de abril de cada un año, se hagan doze anatomías, explicadas con doctrina antigua, y moderna en el Hospital General en público, para la enseñança de los Mancebos Platicantes, à la qual concurrirán todos, para que sobre ellas tengan sus conferencias" (Figural1).

Martín Martínez fue una figura importante de la Anatomía española. Los orígenes de su saber anatómico se hallan por una parte en su gran formación libresca y de otra, por las enseñanzas que obtuvo al asistir a las explicaciones de Florencio Kelli, "Dissector Regio" de Madrid (1,9).

Se le podría considerar como el principal organizador de la citada primera Cátedra de esta disciplina en el Hospital General. Debió ser el primero que impartió públicamente, en España, lecciones de anatomía sobre cadáveres humanos. Estas demostraciones anatómicas que hacía en el Hospital, eran conocidas por el pueblo madrileño y acudían a verlas tanto compañeros como paisanos. Se dice que el propio Rey a veces iba acompañado de personajes de la Corte $(1,15)$.

Era su deseo que tales explicaciones anatómicas pudieran servir al estudiante y al clínico, más concretamente al cirujano, para que mejorara su ejercicio profesional. Además, como él mismo confiesa, lo exponía con sencillez para poder "excitar esta afición a la anatomía" muy olvidada en España en aquella época (14).

Sus escritos sobre esta materia fueron los primeros dirigidos a la enseñanza. Presentaban una intencionada relación entre la anatomía y la cirugía, que él justifica en diversas ocasiones, como, por ejemplo al escribir en el prólogo del Compendio y Examen Nuevo de Cirugía Moderna: "la cirugía es una feliz consecuencia de la Anatomía, de cuya fuente de noticias se deriva el raudal de sus operaciones" (14).

La importancia de Martín Martínez fue muy grande, pues difundió el saber anatómico de los autores anteriores a él, dando a sus escritos un carácter

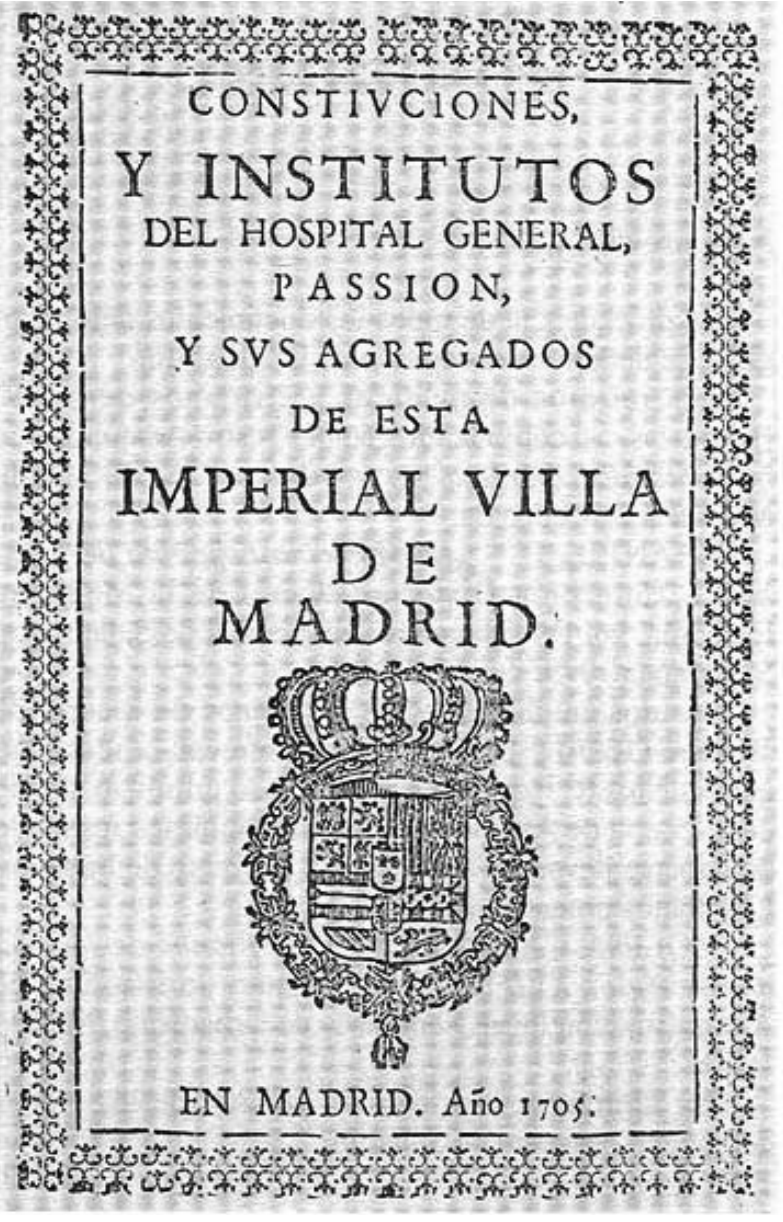

FIGURA 1 1. Portada del libro de las "Constituciones y Institutos del Hospital General, Passion, y sus agregados" de 1705

personal y original. Muchas veces dio más importancia a las cuestiones fisiológicas, y hasta clínicas, que a la morfología, que describe sobriamente.

Además, sus libros de anatomía los escribió en castellano, lo que fue un avance comparado con otros de esa época. Todo ello explica el gran influjo que sus obras ejercieron en la formación de los médicos españoles del siglo XVIII (1).

Su primer escrito anatómico fue, Noches Anatómicas, cuyo texto encabeza una censura elogiosa, de Boix y Moliner. La obra está compuesta de 14 partes o "Noches" y en cada una se aprecia un diálogo entre un doctor, reencarnación del autor, y un cirujano a quien busca aleccionar. Le sigue, a cada diálogo, la propia lección anatómica. Al final añade un vocabulario anatómico (9).

\footnotetext{
${ }^{11}$ Fueron sucesivamente Catedráticos de Anatomía de dicho Hospital: José Arboleda, como ya se ha dicho (hasta 1707), Martín Martínez (hasta 1734), Bernardo López de Araujo (hasta 1762), Juan Gámez (hasta 1790) y Antonio Dámaso Torrecilla. Estos Catedráticos eran auxiliados por disectores anatómicos, como Vicente Gilalbert, Florencio Kelli, Blas Beaumont, Rossen, Juan de Dios López y José Fernández.
} 

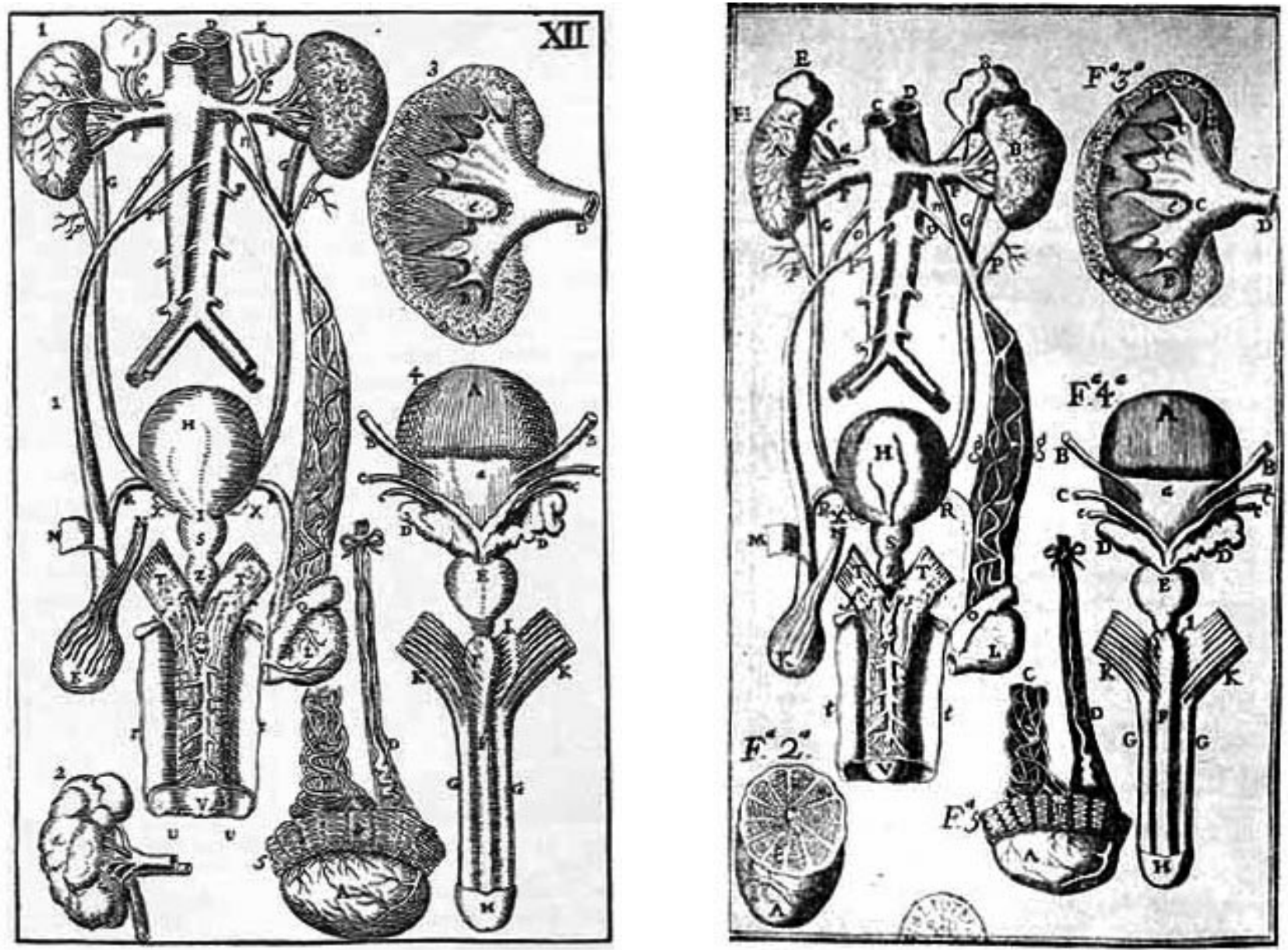

FIGURA 12. Comparación de la lámina XII del libro de Verheijen y la lámina VI del libro de Martín Martínez Anatomía Completa del Hombre en su edición de 1764.

La descripción morfológica sigue un criterio funcional o fisiológico, por lo que en los capítulos de "esplagnología" trata de los órganos de la "chilificación", de los que "purifican la sangre" (aquí estudia el aparato urinario) y de los "de la generación", en ambos sexos.

Después de esta obra escribió un breve epítome de anatomía, que incluyó como primer tratado en su libro "Compendio y Examen Nuevo de la Cirugía Moderna" (9).

Su tercera obra fue Anatomía Completa del Hombre, con la que pretendió completar las anteriores. Aunque fue un resumen del conocimiento anatómico de la época, sin aportaciones nuevas, constituyó la obra más importante de entonces y se convirtió en un libro de texto durante muchos años. La dedicó a Cervi, primer médico de cámara de Felipe V, y gran protector de la medicina española de la época. La obra lleva laudatorias censuras de los doctores José Suñol y Francisco Perena $(11,14,19)$.

Ordenó su texto en un Tratado Proemial ${ }^{12}$ y cuatro Tratados más, que se corresponden con 12 Lecciones. Cada Lección a su vez está dividida en Capítulos. Incluyó 23 láminas grabadas por Matías de Irala, para ayudar a comprender mejor lo que explicaba el texto, alguna de ellas tomadas de obras de otros países ${ }^{13}$ (Figura 12).

El Tratado I es el más amplio. Describe "el Vientre Inferior" (Figura 13), estudiando en él los mismos órganos ya citados en su primera obra: de "chi-

12 En el Tratado Proemial, dividido en 9 Capítulos, escribe en el Primero: "...es la anatomía el fundamento más demostrativo, y evidente de la medicina, y cirugía..." y continúa "es una disección, ò separación artificiosa de las partes del cuerpo humano para que se conozca el oficio de cada una, y se curen con acierto las enfermedades."

${ }^{13}$ Ejemplo de ello es la Estampa 6 copiada con muy pocas variaciones de la XII del libro Anatomia Corporis Humani (Lovaina, 1693) de Philipp Verheijen. 


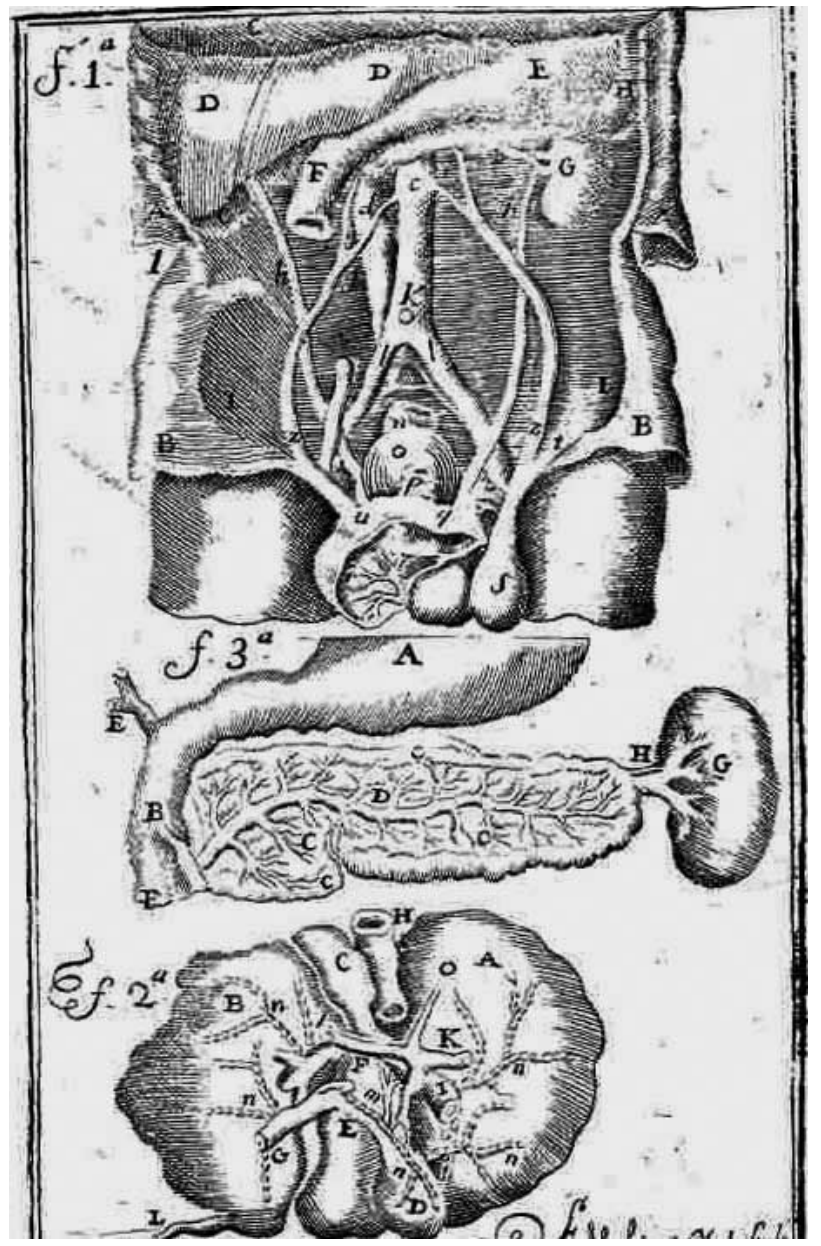

FIGURA 13. Lámina que representa el Vientre Inferior en el citado libro de Anatomía de Martín Martínez.

lificación", de "purificación de la sangre" y los de "la generación". El Tratado II estudia la cavidad torácica y sus vísceras, así como sus funciones (circulatoria y respiratoria). El Tratado III se refiere a la morfología del sistema nervioso central y a los órganos de los sentidos, junto con reflexiones fisiológicas. El IV trata de las extremidades, de la osteología, miología y angiología. Son de interés las reflexiones fisiológicas que intercala, así como la alusión a temas patológicos.

A continuación trataremos algunas consideraciones extraídas de la lectura de las 5 Lecciones del Tratado Primero de la Edición de 1764 (14) (Figura 14).

En el Capítulo 5 de la Lección III, describe los Riñones, Uréteres y Vexiga. Habla de su situación, morfología, irrigación, inervación (los nervios les dan a los uréteres "el exquisito sentido, que experimentan los nefriticos"). Describe también la penetración de

\section{ANA TOMT A COMPLETA DEL HOMBRE, CON TODOS LOS HALLAZGOS, NUEV.AS DOCTRINAS, \\ X. OBSERVACIONES RARAS \\ HASTA EL TIEMPO PRESENTE, $\checkmark$ MUCHAS ADVERTENCIA; NECESSARIAS: \\ PARA LA CIRUGIA: \\ SEGUN EL METHODO CON QUE SE EXPLICA \\ EN NUESTRO THEATRO DE MADRID. \\ $P \circ R$ \\ EL DOCTOR DON MARTIN MARTINEZ, \\ Medico de Camara de fu Mageftad, Socio, y Ex-Prefidenses \\ de la Regia Sociedad de Sevilla, Profeffor P*blice. ds Axatoraia, , y Examinador que fue de fu Real , Proto-Medicato. nemse CON LIC ENCIA. \\ EN MADRID : En la Imprenta de la Viuda de Manuel Se ballatio ernandez. Ario de 1764 .

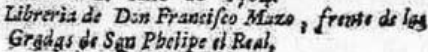

FIGURA 14. Contraportada del mismo libro de Martín Martínez.

los uréteres en la vejiga con el efecto de "que no puede retroceder la orina". Así como las característica de la orina de la que "toman mucha luz los Médicos para sus pronósticos en las enfermedades".

Queriendo explicar el rápido efecto diurético de algunos medicamentos o bebidas, así como el que hubiera orina en la vejiga de un perro al que habían ligado los uréteres previamente, concluye:

"...que huvo otras vías por donde pudo baxar" la orina. "Corrobora el assumpto, haverse visto salir con la orina, según auténticos testimonios, cosas muy gruesas, como agujas, clavos hongos, huesos de frutas..." Según él "... hay una orina de la bebida, que sale sin mixtion ${ }^{14}$, ni alteración, y otra que va por las vías comunes, padeciendo muchas mixtiones en los vasos, y entrañas". clusión de:

Después de varias conjeturas llega a la con-

\footnotetext{
${ }_{14}^{14}$ Mixtion: La mezcla o ayuntamiento de unas cosas con otras. (Diccionario de Autoridades de la Real Academia. 1737).
} 
"que desde los vasos lácteos" 15 hy conductos, que van derechamente a la vexiga,... los quales ordinariamente están cerrados..." "Y baste esta conjetura, hasta que algún feliz Colón, entre otros aún ignorados conductos, descubra estos, borrando el Non Plus Ultra, que parece han puesto en esta Profesión los Anatómicos de los passados siglos."

En la página 152 describe varias anomalías renales: riñones únicos, dobles, en herradura:

"En nuestro Theatro de Madrid a fin del año passado don Blas Beaumont, Disector Anatómicos, en el Cadáver de un hombre halló un solo Riñón, por todas circunstancias monstruoso... su figura era semicircular, con las dos puntas azia arriba..." (Figura 15).

Se refiere después a otros casos anómalos descritos por Ballonio, Bartholino, Scheffero y Riolano.

Luego describe anomalías ureterales como la duplicidad observada por él, con su maestro Kelli:

"...don Florencio Kelli en Madrid a 8 de marzo de 1707, era el tal riñón no más grande que un huevo de Paloma, de figura Cónica: de el salían dos uréteres,..."

Sobre dilataciones ureterales refiere, el caso de Colbert, Ministro del Rey de Francia. En su cadáver los uréteres "se encontraron tan anchos, que contenían muy gruesas piedras".

En la página 154 describe la Vexiga. Habla de Su magnitud, Su fondo y Su cerviz. Aquí hace una observación:

"Tiene este cuello en su orificio un músculo circular llamado Esphincter por medio de cuya acción le abrimos, o cerramos voluntariamente: y se observa quando passan los excrementos $\operatorname{crasos}^{16}$ por el Recto, que se detiene la orina, y que aunque queramos, no puede salir ambas cosas a un tiempo: y es, porque los excrementos crasos con su corporatura comprimen la cerviz, quando passan por el Recto".

También describe con precisión Su unión, Sus túnicas, Sus vasos, Sus agujeros y Su uso.

Describe la retención de orina (Iscuria) y sus causas: dilatación vesical por no evacuarla a tiempo;

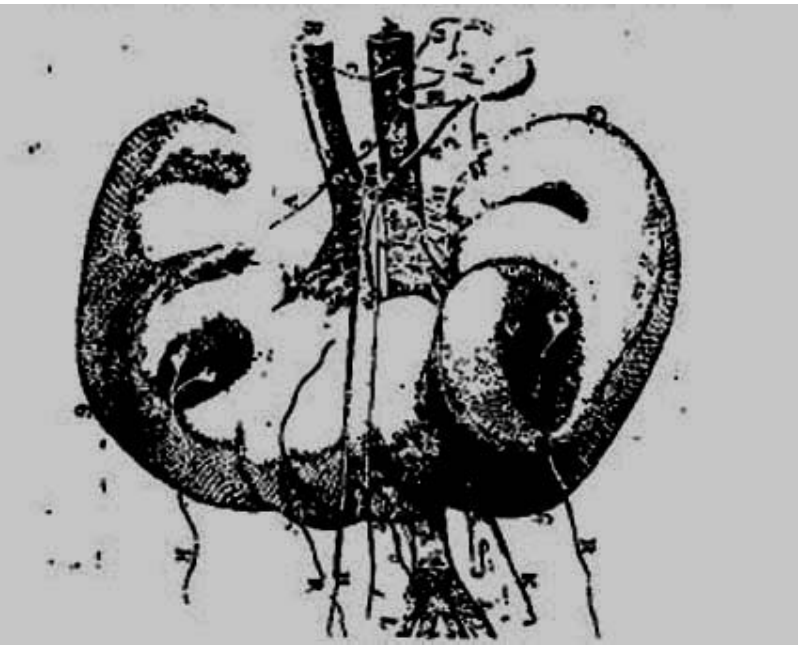

FIGURA 15. Riñón en herradura descrito por Blas Beaumont.

por cuerpos extraños "que estorvan la salida de la orina"; o por "Convulsión, o Inflamación del Esphincter; o por Relaxación de las Fibras Musculosas de la Vexiga,..."

Pasa a exponer después algunos "Casos Raros": vejiga pequeña, doble, ausencia de ella, etc.

En el Capítulo 1 de la Lección IV, describe los Vasos Espermáticos y Testículos. Después de referirse al origen y situación de las arterias, describe las venas con sus válvulas (no menciona que sean escasas e incompletas) y diferente abocamiento de cada una de ellas.

"la naturaleza... no sólo las puso Valvulas à trechos, que sirviesen como de escalones, y descansos, para que una vez ascendido, no pese sobre los de abaxo, sino insertó la Vena Espermática izquierda en la Emulgente izquierda, y no en la Cava, para que la pulsación de la Aorta, que está al passo, no sirviese de estorvo a la sangre, que sube por la dicha Espermática".

Se refiere a por qué los Antiguos llamaron a los vasos espermáticos Preparantes demostrando que no se les debe considerar como tales. Se creía antiguamente

"que la Arteria, y Vena se entrelazaban con varias Anastomoses en el Plexo Pampiniforme, y en el mezclandose la sangre Arterial, y Venal, recibía la primera preparación para convertirse en Semen".

\footnotetext{
15 Lácteo: Lo que pertenece a leche, ò se le parece. (Diccionario de Autoridades de la Real Academia. 1737). (Debe referirse a vasos linfáticos)
}

16 Crasso: Gruesso, gordo, pingüe y espeso. (Diccionario de Autoridades de la Real Academia. 1737) 
Pasa a continuación a hablar de los Testículos y de sus denominaciones, su función, su figura y magnitud". Refuta la idea antigua de que el testículo derecho engendraba varones ya que producía mejor semen. Refiriéndose a Sus túnicas describe detenidamente el Scroto y una de sus afecciones: el Emphisema ${ }^{17}$.

Describe luego la túnica de Dartos, la Eritroide, la Vaginal y la Albuginea. Explica que hay tres clases de hidroceles o hernias acuosas, según "las aguas se derraman entre las túnicas".

Pasa después a hablar de la "substancia de los Testículos" formada por

"un ovillo de sutilísimos Vasos, o Canales seminales arrollados, que si se estendieran sin romperse, tendría muy bien veinte, ò treinta varas de largo..."

Padecen "...demás de otros tumores comunes a otras partes, están sujetos a las Hernias venéreas, que suelen venir después de una gonorrea virulenta,... causando un tumor duro, y de naturaleza scirrosa, y a veces Sarcocele o una Gangrena, que no puede curarse sin la obra de la castración".

Después de hablar de los músculos Cremásteres, habla del Uso de los testículos y de cómo se forma el semen en ellos y no en las Vesículas Seminarias como otros creían ${ }^{18}$.

"Casos Raros": Falta de arterias espermáticas. En el Anfiteatro de Madrid vio una vez que la Arteria espermática izquierda nacía de la Emulgente de su lado.

Cita autores que encontraron sólo un testículo y otros hasta tres. Sobre su situación refiere que los que los tienen escondidos:

"se llaman Testicondos y esta experimentado, que son más venéreos, que los Dídimos, esto es, los que los tienen descubiertos, y assí no es causa de infecundidad, ni motivos de divorcio, como prueba Paulo Zachias en sus Questiones Médico-Legales".

Cuenta de un autor que describió el caso de un niño, que nació con los testículos y el escroto en el
Occipucio. Y de otro, que refiere el caso de un monje "continentisimo" que tenía los testículos y sus vasos "del todo secos". Él observó un hombre de cuarenta años que por "demasiada continencia, y falta de uso tenía inhábiles y como paralíticos los instrumentos de la erección..."

En el Capítulo 2 de la misma Lección trata "Del Epididimis, Vasos Deferentes, Vesículas y Próstatas". Describe minuciosamente cada uno de ellos y su función. Refiriéndose a las vesículas describe la gran relación que tienen con el Recto:

"... y así hay personas, que con el calor de una lavativa vierten el Esperma, por razón de esta unión y simpatía del Recto, con las Vesículas".

Describe a continuación los Vasos Yaculatorios y su abocamiento en el Verumontano. Advierte:

"Algunos Cirujanos quando meten la Candelilla, hallando el estorvo de esta Carúncula, que llamamos Verumontano, juzgan que es carnosidad superflua, y con grave daño de los pacientes, introducen Cáusticos para consumirla: por ello es necesario poner esta advertencia, para que los principiantes se acostumbren a discernir la que es natural de la carúncula preternatural".

En cuanto a su función dice:

"... quando las membranas de las vesículas seminales les aprietan, exprimen el Esperma espumoso, que al salir por estos vasos Yaculatorios lque le impelen) causa por su exquisitisimo sentido aquella voluptuosa titilación, que llamo Demócrito pequeña Epilepsia: y assí por no haverse descubierto estas Vías, se equivocaron los Antiguos, creyendo que esta sensación era causada por el impetuoso éxito del semen, por los Orificios de las Próstatas."

Describe a continuación las Próstatas como dos cuerpos glandulosos, ovalados y algo duros que exprimen

"un humor blanco, y viscoso, parecido a la clara de huevo, que sale por diez u doze Vasos excretorios al Canal de la uretra, cerca del Verumonta-

\footnotetext{
17 Cita una gangrena gaseosa con las siguientes palabras. La observó "...en un hijo de Juan de Peñas... el cuál provino de una Úlcera sobre el llion derecho, después de un abscesso improprio. En este fue tal la hinchazón del abdomen, escroto, y partes inferiores, que con supresión de orina, y fiebre maligna, y coagulatoria, pereció en pocos días".

${ }^{18}$ En aquel tiempo el concepto de semen era el siguiente: Materia húmeda, caliente, espumosa, y blanca, formada del residuo del alimento, que depositada en vasos convenientes, y cocida, y elaborada en los testículos, sirve para la generación del animal. (Diccionario de Autoridades de la Real Academia. 1737). La explicación que da Martín Martínez es aún más compleja.
} 
no". "El uso del liquor viscoso que destilan, es bañar la superficies de la Uretra, para defenderla de la acrimonia de la orina, y en el Coito servir de vehículo al Semen, porque no se peguen las paredes de este Canal, sino resvale, y llegue al lugar de su destino".

Explica la causa de la gonorrea al fluir continuo del humor viscoso de la próstata, al estar afectada por un vapor corrosivo y maligno. Este también afecta a la uretra y otras glándulas, lo que produce un gran ardor y dolor al orinar. Consecuencia de ello es también el dolor en la erección y curvatura por la uretra inflamada y ulcerada. Esto motiva cicatrices que:

"estorvan la fácil salida de la orina las cuales tienen algunos por carnosidades superfluas, e imprudentemente con grave daño de los sugetos introducen cáusticos para carúnculas" lo que suele producir "una total supresión de orina, y a veces abcessos, fistulas, y úlceras incurables".

Para curar los síntomas consecuentes a la gonorrea aconseja

"Dieta refrigerante, sangrías, lavativas, baños, emulsiones, e inyecciones atemperantes llas que moderan y ablandan), después de quales remedios, con sólo una tienta de plomo graduada, se suele hacer salir fácilmente la orina".

Termina el capítulo hablando de las glándulas de "Couper, Anatómico Inglés" a la que denomina "nuevas Próstatas".

En Capítulo 3 de la misma Lección IV trata del Miembro Viril. Describe sus partes: Cutis, Cuerpos cavernosos, su División membranosa y la Uretra. Sobre esta, afirman que su:

"cavidad es casi igual en toda su longitud, sólo en su fin hay una como Cavernilla, donde suele pararse con gran dolor el Cálculo, y el humor acre de la Gonorrea..."

Refiriéndose a su forma explica:

"esta figura deben notar los Cirujanos, para introducir diestramente, y sin detrimento la Candelilla en la cavidad de la vexiga".

Ya que es paso común de la orina y el semen "tiene quatro muy considerables agujeros", pero además tiene otros "pequeñisimos agujeros" correspondientes a "las Próstatas" y otras glándulas.
En una Lección posterior, refiriéndose al Conducto Urinario de la mujer, expone:

"...por ser mas corto, y ancho, orinan las mugeres mas presto, y no padecen tan frecuentemente del Calculo, porque el facil, y prometo éxito de la orina no dexa de tener los sabulos ${ }^{19}$, o arenas, que suelen formarla".

Describe a continuación el glande que tiene una:

"delicadísima membrana que lo cubre, de cuya confricación procede gran parte del deleyte sensual..." Comenta que a veces no hay agujero de meato y los que así nacen "corren riesgo, sino se da providencia de abrirlo..."

Describe el Prepucio, el Frenillo, la enfermedad por Phimosis y la Paraphimosis. "... si el Prepucio se corta circularmente, o por enfermedad, o por Rito Judayco, esta operación se llama Circuncisión".

Son muy curiosas las ideas que aporta en el Capítulo 4 de la Lección V, referente a la Generación. Después de refutar 3 teorías antiguas explica su hipótesis semejando la función de la Generacion a la función de la Nutricion.

Terminaremos diciendo que sobre esta obra: Anatomía Completa del Hombre, hay juicios positivos como los que emitieron Feijoo, Fernández Morejón, Menéndez y Pelayo, López Piñero y Granjel. Los libros que se habían publicado hasta esas fechas en España sobre anatomía, no reflejaban nunca los aspectos fisiológicos y clínicos, lo que fue muy frecuente en las obras de Martín Martínez.

Pero también hay juicios negativos, como son los de Lorenzo Hervás, Víctor Escribano, García del Real y Marañón. Según ellos tiene errores y descuidos por lo que consideran su libro de menos calidad que el escrito por Valverde dos siglos antes $(2,3)$.

\section{CONCLUSIONES}

Aunque la medicina oficial fue poco brillante, como opinaban Marañón y otros autores, fue resplandeciente al amparo de lo oficioso, como opina Piñero y Granjel, por lo que se salvó la Cultura Española de aquella época.

A ello contribuyó Pedro Martín Martínez que, en palabras de Cruz del Pozo (3), "fue un mé-

\footnotetext{
${ }_{19}$ Sabulo: La arena crassa y pesada. (Diccionario de Autoridades de la Real Academia. 1737)
} 
dico humanista con continuas llamadas a la libertad de pensar; y aunque no le podamos atribuir contribuciones sustanciales al desarrollo de los conocimientos científicos sobre la naturaleza, sí podemos reconocerle la aportación de introducir los ideales de la modernidad en un ambiente hostil, de marcar la vía del uso libre de la razón y, a la vez, de defender la experiencia como criterio metodológico. Sus obras pusieron a disposición de la gente un resumen de los saberes modernos, por lo que se le debe considerar como uno de los participantes en el movimiento de emancipación de la escolástica".

Hay también que valorarlo más, teniendo en cuenta que nunca pudo hacer viajes pensionados de estudio al extranjero, como hicieran antes y después otros médicos (1).

\section{BIBLIOGRAFÍA y LECTURAS RECOMENDADAS ( ${ }^{*}$ lectura de interés $y^{* *}$ lectura fundamental)}

*1. ÁLVAREZ SIERRA, J.: "Anatómicos madrileños famosos". Instituto de Estudios Madrileños. Madrid. 1953.

2. CIFUENTES DÍAZ, P.: "Bosquejo histórico de la urología en España anterior al siglo XIX". Discurso leído en la solemne Sesión Inaugural celebrada el día 16 de marzo de 1945 en la Real Academia de Medicina”. Pág. 86. Imprenta de J. Cosano. Madrid. 1945.

*3. CRUZ DEL POZO, M. V.: "Los inicios de la modernidad en España: la aportación de un Médico Filósofo". I Jornadas de Medicina y Filosofía. Disponible en: URL: http://www.cica.es/aliens/dflus/ medicinayfilosofia/ContenidoIjornadas.htm

4. FEIJOO, B. G.: "Teatro crítico universal". Tomo cuarto, discurso cuarto. Biblioteca Feijoniana. Edición digital de las obra de Feijóo. Proyecto Filosofía en español. Disponible en: URL: http://www. filosofia.org/feijoo.htm

5. FEIJOO, B. J.: "Apología del Escepticismo Médico". Texto tomado de la edición de Madrid de 1777. Biblioteca Feijooniana. Edición digital de las obras de Feijóo. Proyecto Filosofía en español. Disponible en: URL: http://www.filosofia.org/feijoo.htm

6. GARCÍA CUERPO, E.; LOVACO CASTELLANO, F.; SÁNCHEZ ENCINAS, M: "La Urología Española de la Ilustración". En: "Historia Biográfica y Bibliográfica de la Urología Española". Capítulo III. Pág. 127-182. Oficina de Historia de la Asociación Española de Urología. Edicomplet. Madrid. 2000.

7. GIMÉNEZ MÁS, J. A. : "El microscopio del Padre Feijoo. En el preludio de la Patología de Morgagni." Rev Esp Patol, vol. 37, no 1: 111-120. 2004.

8. GRANJEL, L. S. "Humanismo médico renacentis- ta" En Laín Entralgo, P.: "Historia Universal de la Medicina". Primera edición. Salvat Editores, S.A. Tomó IV, pág. 38 y sig . Barcelona. 1972.

*9. GRANJEL, L. S. "La obra anatómica de Martín Martínez". Boletín de la Sociedad Española de Historia de la Medicina. Vol. I. No 1. Madrid, 1960.

10. GUTIERREZ SESMA, J.: "El padre Isla y los médicos españoles del siglo XVIII". Medicina e Historia. No 7. Pág. 1-16. Barcelona. 1971.

11. INSAUSTI CORDON, J.L.: "Afinidad anatomía urología”. Actas Urol. Esp. Vol. II. Núm. 2. 1978.

12. MARAÑóN, G.: "Nuestro siglo XVIII y las Academias". En "Vida e Historia". Pág. 40-68. Tercera edición. Colección Austral. Espasa-Calpe, S.A. Madrid. 1943.

13. MARTÍN MARTÍNEZ, P.: "Carta defensiva sobre el primer tomo del Teatro Crítico Universal escrito por el padre Feijoo". Disponible en: URL: http:// www.filosofia.org./ave/001/a023.htm

**14. MARTÍN MARTÍNEZ, P.: "Anatomia Completa del Hombre, con todos los Hallazgos, Nuevas Doctrinas y Observaciones Raras hasta el Tiempo Presente, y muchas Advertencias Necessarias para la Cirugia segun el Methodo con que se explica en Nuestro Theatro de Madrid". En Madrid: En la Imprenta de la Viuda de Manuel Fernandez, Año 1764. Libro digitalizado disponible en: URL: htpp: //alfama.sim.ucm.es/dioscorides/temp/

*15. NUÑEZ OLARTE, J.M.: "El Hospital General de Madrid en el siglo XVIII". Cuadernos Galileo de Historia de la Ciencia. No 19. Pág. 65-73 y 201209. Madrid. 1999.

16. PÉREZ ALBACETE, M.: "Patología urológica en las memorias y censuras de las Juntas Literarias del Real Colegio de San Carlos de Madrid (17881834)". Arch. Esp. Urol. 55, 5 (483-495). 2002.

17. PÉREZ ALBACETE, M.: "100 figuras de la Urología Española". Oficina de Historia de la Asociación Española de Urología. Pág. 48 y 49. Tipografía San Francisco, S.A. Murcia 2005.

18. REY BUENO, M. M.: "Medicina y Farmacia Cortesana: estudio de la organización sanitaria la corte española (1548-1700)". Alma Mater, número 16, 1999. Disponible en: URL: http://sisbib.unmsm. edu.pe/ BibVirtual/Publicaciones/Alma Mater

19. RIERA PALMERO, J.: "La Urología española del siglo XVIII". Cuadernos de Historia de la Medicina Española. IV, no 1, Pág. 55-89. Madrid. 1965.

20. RODRÍGUEZ SÁNCHEZ, R. Á.: "Algunos aspectos de la Ciencia Universitaria en la Modernidad Española". I Jornadas de Medicina y Filosofía. Universidad de Sevilla. Facultad de Filosofía. Disponible en: URL: http://www.cica.es/aliens/dflus/ medicinayfilosofia/ContenidoIjornadas.htm

21. TORRES VILLARROEL, D.: "El Hermitaño, y Torres". Salamanca 1752. Libro digitalizado disponible en: URL: htpp://alfama.sim.ucm.es/dioscorides/foldeltree 